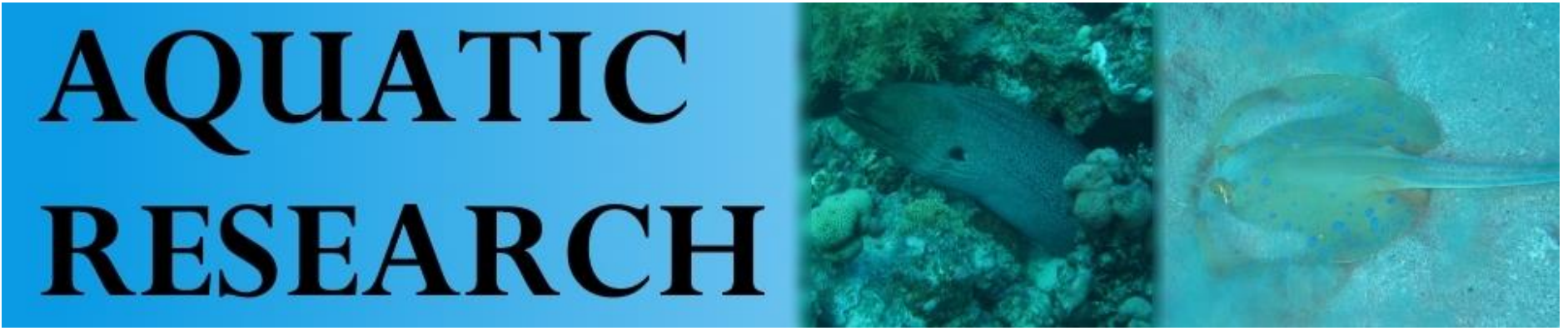

\title{
BEHAVIOR AND RESPONSE OF JAPANESE CATFISH (Silurus asotus) IN CAPTIVITY PROVIDED WITH AN ARTIFICIAL MICROHABITAT MOSAIC
}

\author{
Nur Efah Arsin $\stackrel{\text { iD }}{-}$, Abentin Estim $\stackrel{\text { iD }}{-}$, Saleem Mustafa iD
}

\section{Cite this article as:}

Arsin, N.E., Estim, A., Mustafa, S. (2018). Behavior and Response of Japanese Catfish (Silurus asotus) in Captivity Provided with an Artificial Microhabitat Mosaic. Aquatic Research, 1(3), 136-139. DOI: 10.3153/AR18015

Borneo Marine Research Institute, Universiti Malaysia Sabah, 88400 Kota Kinabalu, Sabah, Malaysia

Submitted: 05.04.2017

Accepted: 11.04.2018

Published online: 13.04 .2018

Correspondence: Saleem MUSTAFA

E-mail: saleem@ums.edu.my

๑) Copyright 2018 by ScientificWebJournals

Available online at

http://aquatres.scientificwebjournals.com

\begin{abstract}
Rearing of Japanese catfish (Silurus asotus) requires special considerations for designing of facilities and management. Information on its biology in natural environment provides ideas for developing suitable culture systems. For this species, underwater artificial microhabitat structures are needed to perform its normal behavior. The fish shows distinct preferences for some designs based on visual cues and its decision to make use of these structures is guided by other cues probably related to light and water flow. Microhabitat structures can make a real difference to managing stress of captivity in this species. Absence of a suitable structure causes 'habitat bottleneck' that develops aggressive behavior. However, the intraspecific antagonistic behavior gives way to social tolerance among conspecifics. Microhabitat metrics is important in addition to physical attributes of the structure so as to allow social grouping in the fish under favorable conditions.
\end{abstract}

Keywords: Japanese catfish, Microhabitat, Preferences, Culture system 


\section{Introduction}

Habitat preferences of fish have been a subject of much attention in conservation and management of fish populations (Peterson et al., 2004; Gaillard et al., 2010). Recent years have witnessed a growing interest in mimicking natural conditions in culture systems for reasons of sustainability (Shapawi and Shaleh, 2015). Habitat as a package of resources (food and shelter) and environmental conditions (abiotic and biotic) determines the presence, survival and reproduction of a population (Sinclair et al., 2005). In aquaculture, efforts are made to provide suitable conditions for the stocked species but entirely replicating a vast environment with its enormous variety of resources is not achievable in a limited space. However, it is possible to imitate certain basic features (microhabitat) of the larger ecosystem.

There are many underwater environments and objects but fish selects resources and conditions that enable it to perform normal activities. Obviously, suitability of those microhabitat features would greatly influence the living condition, feeding and growth of the captive stocks. Generally, the animals select structural microhabitat (i.e., available resources or conditions) in a way that is intended to increase their performance while reducing stress (Gaillard et al., 2010). A sustained stress would obviously reduce growth and promote disorderly behavior. Underwater structure in the form of a shelter where fish spends considerable part of its time is an important microhabitat.

In this study an attempt has been made for developing a suitable culture system for the Japanese catfish (Silurus asotus) and for this purpose some essential information on environmental biology of the fish was necessary. A survey of published literature shows that while there is a great deal of interest in habitat selection of many fish species, there is a glaring knowledge gap as far as the Japanese catfish is concerned. The authors are not aware of any published paper on preferences of artificial microhabitats of this fish in a culture system. A pertinent research hypothesis for this study is to accept the microhabitat selection by the fish in a culture system as a process of behavioral response and making choices which would influence its condition. The objective of this work is limited to observing the artificial microhabitat preferences of the catfish when provided with a mosaic of underwater structures in the culture tanks.

\section{Materials and Methods}

Specimens of the Japanese catfish from the same stock averaging $16.9 \mathrm{~cm}$ and weighing $30 \mathrm{~g}$ were selected for the experimental trials. This size group of a sibling class was available in adequate numbers for the experiment. After 7 days of acclimatization in the hatchery, the fish were stocked at the rate of 10 specimens/ton The tanks (5-ton capacity) were aerated to maintain dissolved oxygen in the range of 5-6 ppm. The fish were offered pellet feed daily at the rate of $3 \%$ of body weight. Feed was supplied by a local company, Leong Hup Feedmill Private Limited. This feed is considered suitable generally for tropical carnivorous catfishes that require protein-rich diets.

Water was renewed daily in the morning to remove waste and maintain a good environment for the fish. One tank that served as control did not contain any artificial microhabitat (AH0) while the others were provided with underwater rounded and elongated structures of different designs that included: green high-density polyethylene net (AH1) (Figure 1a), green plastic grass structure (AH2) (Figure 1b) green polyvinyl chloride pipe (AH3) (Figure 1c), and grey polyvinyl pipe (AH4) (Figure 1d). These structures were similar in length $(30 \mathrm{~cm})$ and diameter $(8 \mathrm{~cm})$. Observations on the behavior of captive fish were made during day and night. These included their activities related to feeding, preference for underwater structures, swimming and other activities. Except the control set (AH0) that contained no microhabitat structure, all the other underwater structures (AH1, $\mathrm{AH} 2, \mathrm{AH} 3, \mathrm{AH} 4$ ) were placed in the same tank so as to offer equal choice to the fish to select the microhabitat structure according to its preferences. Experiment lasted three weeks. This period was enough to establish microhabitat preferences of the fish because the pattern was repeated, with no departure or exceptions under conditions the fish was exposed to.

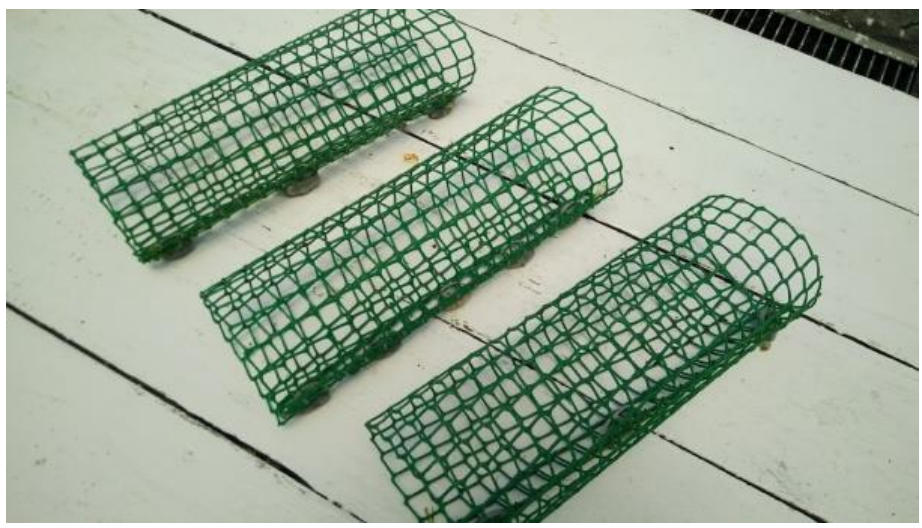

Figure 1a. Green HDPE net artificial substrate (AH1) 


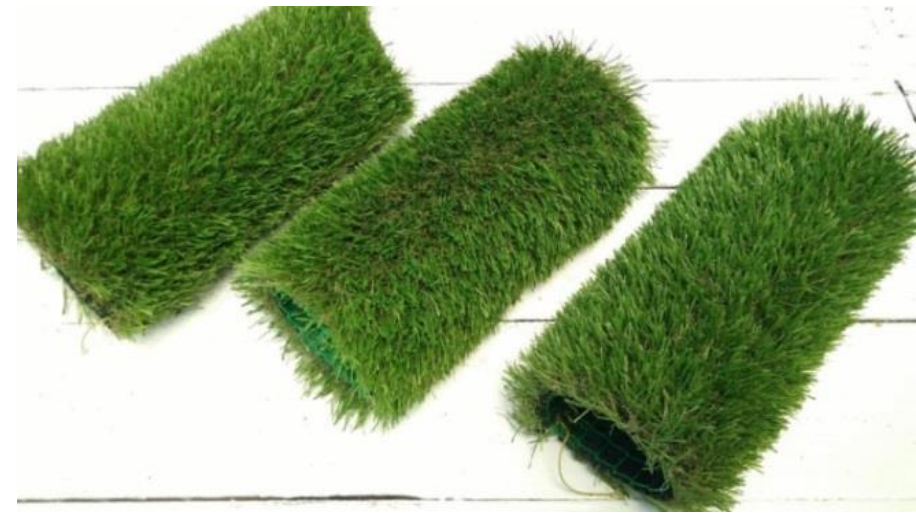

Figure 1b. Green artificial grass structure (AH2)

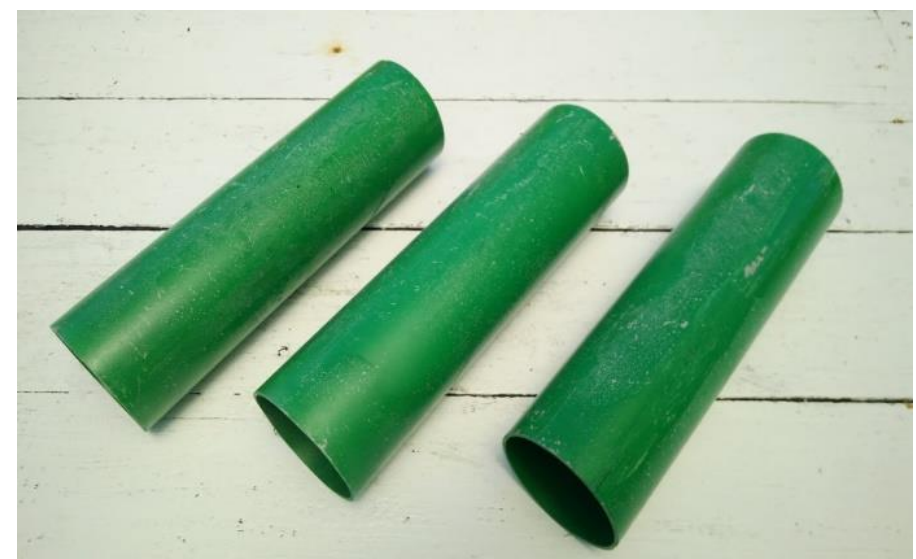

Figure 1c. Green PVC structure (AH3)

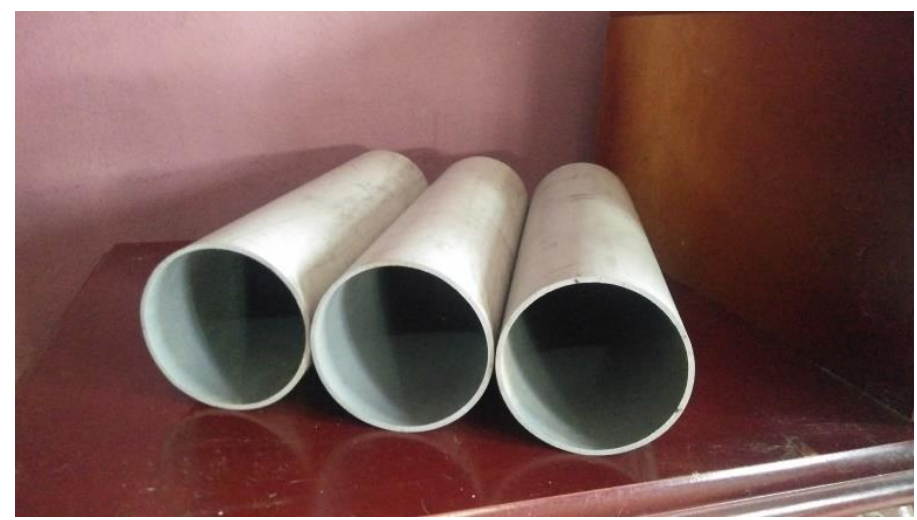

Figure 1d. Grey PVC structure (AH4).

\section{Results and Discussion}

Japanese catfish showed nocturnal feeding habit. Generally, it was inactive during the day but moved freely at night, actively looking for food. The fish did not pick up food from water column but consumed when it settled down at the tank bottom.
During the day, in tank without underwater structure (AH0), the fish showed obvious signs of stress in the form of unusual frantic movement and frequent rubbing against tank bottom. The stress appeared to have resulted in extreme aggression among conspecifics that were seen biting and injuring each other.

In order to determine what types of underwater structures can contribute to welfare of the fish, its response to a mosaic of four artificial microhabitat structures was observed. Fish were seen entering the structure AH1 that allowed a free flow of water and did not curtail light penetration. Installing structure $\mathrm{AH} 2$ next to $\mathrm{AH} 1$ resulted in the fish moving out of the latter and entering $\mathrm{AH} 2$ whose surface was grassy in design.

Placing other structures (AH3 and AH4) provided better insights into microhabitat selection. The fish entered $\mathrm{AH} 3$ and AH4 and showed no tendency to move out throughout the day. The AH3 and AH4 structures were devoid of mesh holes of the type developed for AH1 and perforations designed for AH2. These were made up of solid walls that provided more stable conditions, prevented water flow from sides and curtailed light penetration. Probably, in the dim internal environment of these opaque structures the preference for background color was not so important.

When the fish entered the stable microhabitat structures there was no aggressive behavior even though the specimens were in close proximity. Obviously, stress of not being able to find a suitable underwater shelter turns into aggression. Interestingly, this intraspecific antagonism is not a continuous process or an inherent behavior, since the same individuals interacted differently in a short period of time when conditions changed. The antagonism was strong, in the form of indulgence of physical harm, but the way it rapidly pacified when the shelter was made available was remarkable.

Nocturnal feeding behavior of the fish seen in this study is concordant with the observations made earlier in its native environment by Dulmaa (1999) and Kim et al. (2005). This pattern of behavior is probably linked to negative buoyancy of heavy anterior region and small swim bladder that do not support active forays in the water column for extended periods.

Tendency of the fish to enter the artificial microhabitat structures is consistent with its behavior of hiding under submerged objects during day time in the natural habitat. Thus, absence of any facility for shelter in the tank (AH0) was the reason for stress and aggression. Aggressive behavior displayed was typical of captive fish under stress as documented by HMC (2015). Oldfield (2011) also observed 
cichlid fish in the aquarium and attributed aggression to lack of optimum conditions.

It is possible that in the absence of a microhabitat mosaic, the fish would prefer having any shelter (AH1) rather than not having any (AHO), and this might leave the fish with no option but to accept whatever physical shelter is available. Lack of a proper artificial microhabitat can be interpreted as a 'habitat bottleneck', which in this case is physical in nature. This is bound to affect the welfare of the captive fish.

It is most likely that a combination of factors, including the grassy appearance of the structure (AH2), and ability of thick artificial grass to impede free flow of water and prevented light penetration accounted for preference for AH2 vis-à-vis AH1. Investigations carried out by Katano et al. (1988) who noticed the Japanese catfish seeking areas with underwater vegetation and studies made by Huckstorf (2012) that revealed the fish's avoidance of fast-flowing water in the rivers lend credence to the present observations.

\section{Conclusion}

It seems that the fish seeks intraspecific social stability except when stress spikes and disrupts it. Based on the above observations on behavior of the catfish, it is evident that microhabitat metrics is important in a culture system. In addition to physical attributes (structure and material stability), size consideration is also necessary since this species has a tendency of staying in groups while resting, and thus the structures should have accommodating size.

\section{Acknowledgement}

This study was supported by Niche Research Grant Scheme (grant code NRGS0001) of the Ministry of Higher Education, Malaysia

\section{References}

Dulmaa, A. (1999). Fish and fisheries in Mongolia. In: Fish and Fisheries at Higher Altitudes: Asia (Petr, T., ed.) pp. 187-236. FAO, Rome.
Gaillard, J-M., Hebblewhite, M., Loison, A., Fuller, M., Powell, R., Basille, M., Moorter, B.V. (2010). Habitat-performance relationships: finding the right metric at a given spatial scale. Philosophical Transactions of the Royal Society of London-Biological Science, 27, 2255-2265.

HMC (2015). Stress in Fish: Symptoms and Solutions. The Hartz Mountain Corporation, NJ, USA.

Huckstorf, V. 2012. Silurus asotus. Amur Catfish. The IUCN Red List of Threatened Species Version 2012.2. www.iucnredlist.org IUCN, ISSN 2307-8235

Katano, O. Saitoh, K., Koizumi, A. (1988). Scatter-spawning of the catfish, Silurus asotus. Japanese Journal of Ichthyology, 35(2), 203-211.

Kim, I.S., Choi, Y., Lee, C.L., Lee, Y.J., Kim, B.J., Kim, J.H. (2005). Illustrated Book of Korean Fishes. Kyo-Hak Publishing Company, Korea.

Oldfield, R.G. (2011). Aggression and welfare in a common aquarium fish, the Midas cichlid. Journal of Applied Animal Welfare, 14(4), 340-360.

Perterson, M.S., Comyns, B., Rakocinski, C. (2004). Defining the fundamental physiological niche of young estuarine fishes and its relationship to understanding distribution, vital metrics, and optimal nursery conditions. Environmental Biology of Fishes, 71, 143-149.

Shapawi, R., Shaleh, S.R.M. (2015). Biology of aquaculture animals- learning from nature to manage culture, pages 3767. In: Aquaculture Ecosystems: Adaptability and Sustainability (Mustafa, S. \& Shapawi, R.,eds.), John Wiley, West Sussex, UK.

Sinclair, A.R.E., Fryxell, J., Caughley, G. (eds). (2005). Wildlife Ecology and Management, 2nd edition, Blackwell Science, London, UK. 